Abstract P245 Table 1

\begin{tabular}{llll}
\hline & Oral Ribavirin & Nebulised Ribavirin & Intravenous Ribavirin \\
\hline $\mathbf{n}$ & 11 & 13 & 10 \\
Mean Age & 52 & 48 & 47 \\
Type of transplant & 4 Bilateral Lung, 4 Single Lung, 3 Heart Lung & 9 Bilateral Lung, 1 Single Lung, 3 Heart Lung. & 7 Bilateral Lung, 1 Single Lung, 2 Heart Lung \\
Gender & $7 \mathrm{M} 4 \mathrm{~F}$ & $7 \mathrm{M} \mathrm{6F}$ & $5 \mathrm{M} \mathrm{5F}$ \\
Mean time since Transplantation (months) & 25.9 & 24.4 & 54.4 \\
Percentage change in FEV1 \pm SD & $96.4 \% \pm 9.9$ & $92.8 \% \pm 14.9$ & $93.3 \% \pm 10.5$ \\
$95 \%$ Confidence interval & $5.84(90.656 / 102.24)$ & $8.11(84.769 / 100.991)$ & $6.50(86.8 / 99.8)$ \\
\hline
\end{tabular}

Results 47 patients were identified. 12 patients were excluded due to insufficient clinical data. Of the remaining 34 patients, 11 were treated with Oral medication, 13 with Nebulised and 10 with Intravenous.

Conclusion Treatment with Ribavirin results in an improvement in lung function. In this small study it appears that there is no difference in lung function between the different routes of administration. Whilst the efficacy appears comparable oral treatment offers significant advantage to the patients and has benefits for treatment cost and bed occupancy.

\section{P246 LUNG TRANSPLANTATION FOR PATIENTS WITH IDIOPATHIC PULMONARY FIBROSIS AND ASYMPTOMATIC CORONARY ARTERY DISEASE}

P Riddell, K Redmond, D Eaton, L Nolke, SH Javadpour, D Healy, J McCarthy, JJ Egan. Mater Misericordiae University Hospital, Dublin, Ireland

\subsection{6/thoraxjnl-2014-206260.374}

Introduction and objectives Lung transplantation significantly improves the survival of patients with advanced idiopathic pulmonary fibrosis (IPF). Concurrent coronary artery disease (CAD) is a relative contraindication to transplantation and can limit access to this therapy. This is particularly relevant as a high prevalence of CAD has been reported in patients with $\mathrm{IPF}^{1}$ We sought to determine whether the presence of asymptomatic CAD impacted upon post-transplant survival.

Methods This retrospective study reviewed all patients who had undergone single lung transplantation for IPF at our centre, between May 2005 to April 2014. We compared post-surgical outcomes for patients with IPF who had an abnormal coronary angiogram (at the time of transplant listing), to those with normal angiography. Kaplan-Meier curves were created to study survival and univarate analysis performed using the Log-Rank score.

Results In this timeframe, 39 patients underwent lung transplantation for IPF, of which 22 patients $(56.4 \%)$ had abnormal coronary angiography. Eight of these patients had minor disease, 5 had $10-30 \%$ stenosis and 5 had $30-50 \%$ stenosis. One patient required coronary artery stenting prior to transplantation, but 3 patients with $\geq 70 \%$ stenosis had no inducible ischaemia on dobutamine stress testing and were managed conservatively. All patients had normal pre-operative left ventricular function.

The post-transplant survival of patients with IPF and CAD was $95.7 \%$ at 1 year and $70.1 \%$ at 5 years. There was no significant difference in survival $(\mathrm{p}=0.52)$ between the cohort with $\mathrm{CAD}$ and those with normal pre-operative coronary angiograms.

Of note, 1 patient required coronary artery stenting 18 months after transplantation (this patient had 30\% LAD stenosis at time of listing). No patients developed chronic arrhythmias, and no patients died as a result of cardiovascular disease.
Conclusion Although CAD remains a relative contraindication to transplantation, the effects of previous PCI or minor CAD are unknown and may be overstated. This finding is particularly relevant for patients with IPF, who may have an increased prevalence of CAD.

\section{REFERENCE}

1 Raghu G, Weycker D, Edelsberg J, Bradford WZ, Oster G. Incidence and prevalence of idiopathic pulmonary fibrosis. Am J Respir Crit Care Med. 2006:174 (7):810-6

\section{P247 MANAGEMENT OF AIRWAY STENOSIS AND BRONCHOMALACIA WITH BIODEGRADABLE STENTS AFTER LUNG TRANSPLANTATION. SINGLE INSTITUTION EXPERIENCE}

${ }^{1} S$ Gelvez-Zapata, ${ }^{1}$ A Wilkinson, 'D Thomas, ${ }^{2} \mathrm{M}$ Pittman, 'J Parmar. ${ }^{1}$ Papworth Hospital, Cambridge, UK, ${ }^{2}$ Basildon and Thurrock University Hospitals, Basildon, UK

\subsection{6/thoraxjnl-2014-206260.375}

Introduction Although the rate of airway stenosis following lung transplantation (LT) has reduced dramatically, it is still a significant cause of morbidity and mortality. Traditional self expanding metallic stents (SEMS) carry a high risk of bleeding and hyperplastic granulation tissue formation. Biodegradable stents (BS) present a potential alternative approach that could reduce these complications, though little is currently known about their effectiveness and safety.

Methods A retrospective analysis of our institutions use of 7 BS (polidioxanone) placed in 6 patients who presented bronchial stenoses after LT between December 2011 and January 2013. 2 patients with single (1 right and 1 left) and 4 with bilateral LT. The indications for placing the stents were anastomotic bronchomalacia in 3 cases and bronchial stenoses in 4 . The outcomes from these stents were compared with the last 10 patients who have SEMS.

Results Re-stenoses recurred in 3 cases, after 10, 6 and 4 months respectively; 2 responded to balloon dilatation and cryotherapy but 1 patient needed repeat stenting for restenosis. Stent migration occurred in 2 cases. No bleeding was reported. One patient died of obliterative bronchiolitis. The mean increase in FEV1 following treatment was a $312 \mathrm{ml}$ increase. Patients required an average of 4.3 (1-9) bronchoscopies following stent

Abstract P247 Table 1 Comparison of the outcomes following biodegradable and metallic stents insertion

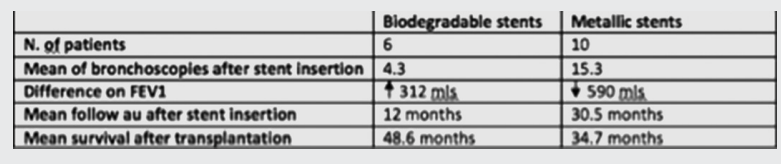


insertion. Mean follow up was 12 months and mean survival 27.2 months. These results compare very favourably with a historical comparator group of the last 10 patients who received MS between 2009 and 2012 who required an average of 15.3 bronchoscopies after MS insertion and who had an overall mean drop in FEV1 of 0.59 L. SEMS have been used for a longer period of time, so follow up in this group was 30.5 months and mean survival 34.7 months (Table 1).

Conclusion Our data add to the limited literature that BS can be a safe alternative to MS for airway stenosis, and may also represent a useful treatment for anastamotic bronchomalacia.

\section{Improving patient therapies in COPD}

\section{P248 CURRENT COPD DISEASE BURDEN ASSOCIATED WITH MAINTENANCE MONOTHERAPY IN THE UK}

'SC Edwards, 'SE Fairbrother, ${ }^{1}$ A Scowcroft, ${ }^{1} \mathrm{~L}$ White, ${ }^{2} \mathrm{BJ}$ Lipworth. ${ }^{1}$ Boehringer Ingelheim Ltd, Bracknell, UK; ${ }^{2}$ Scottish Centre for Respiratory Research, Ninewells Hospital and Medical School, Dundee, UK

\subsection{6/thoraxjnl-2014-206260.376}

Introduction and objectives National Institute for Health and Care Excellence (NICE) recommends long-acting bronchodilators, including $\beta 2$-agonists (LABAs) or muscarinic antagonists (LAMAs) as first line maintenance treatment for patients with COPD. The aim of this descriptive study was to characterise a cohort of COPD patients who were on maintenance bronchodilator monotherapy for at least six months to establish their disease burden, measured by healthcare utilisation.

Methods Data were extracted from the UK Clinical Practice Research Datalink (CPRD) which also linked to Hospital Episode Statistics (HES). The monotherapy period spanned the first prescription of a LABA or LAMA until the end of the study period (31/12/2013) or until step-up to dual/triple therapy; for example the addition of another long acting bronchodilator, an ICS or ICS/LABA. A minimum of four consecutive prescriptions and six months on continuous monotherapy were required for study entry. Patients $<50$ years old at time of first COPD diagnosis or with another significant respiratory disease prior to the start of monotherapy were excluded. Disease burden was evaluated by measuring patients' rate of consultations with a healthcare professional (HCP), COPD-related exacerbations, hospitalisations and referrals to key specialities.

Results A cohort of 8,811 COPD patients (94\% GOLD stage A or B) on maintenance monotherapy was identified between 2002 and $2013 ; 45 \%(\mathrm{~N}=3,947)$ of these patients were still on monotherapy by the end of the study period. The median time from first COPD diagnosis to first monotherapy prescription was 56 days while the median time on maintenance bronchodilator monotherapy was 748 days. The median number of prescriptions during this period was 14 . Patients had a median of 19 HCP consultations and a mean of 0.1 (95\% CI $0.1,0.2, \mathrm{~N}=$ 8,811) COPD exacerbations and 0.02 (95\% CI 0.01, 0.02, $\mathrm{N}=4,848$ ) COPD hospitalisations per year.

Conclusion In summary, COPD patients who are on maintenance bronchodilator monotherapy for at least six months appear to remain on this therapy for over two years despite having a disease burden that requires healthcare resources, particularly HCP consultations, at a cost to the NHS.

\section{P249}

EFFECT SIZE OF OPEN-LABEL VERSUS DOUBLE-BLIND ADMINISTRATION OF TIOTROPIUM IN TRIALS INVESTIGATING HEALTH-RELATED QUALITY OF LIFE IN COPD

H Schmidt, H Kögler, S Geier, T Glaab, I Leimer. Boehringer Ingelheim GmbH and Co. KG, Ingelheim, Germany

\subsection{6/thoraxjnl-2014-206260.377}

Introduction Effects of interventions on patient-reported outcomes may be subjective and modulated by patients' expectations regarding treatment efficacy. The 'gold standard' for minimising such biases are double-blind randomised controlled trials. We analysed the effects of tiotropium on health-related quality of life in chronic obstructive pulmonary disease (COPD) in placebo-controlled trials and assessed whether trial design (doubleblind versus open-label) is a relevant modifier of the effects of tiotropium.

Methods Trials of $\geq 6$ months' duration investigating the effect of tiotropium versus placebo on health-related quality of life in COPD (assessed using St George's Respiratory Questionnaire [SGRQ]) were identified from the Boehringer Ingelheim clinical trial database and by a systematic literature search in MEDLINE, with a cut-off date of 30 November 2011. As a clinical end point, the mean difference between treatment groups in SGRQ total score was assessed. Trials were grouped according to double-blind or open-label design. We performed a network metaanalysis including standard methodology to test for interaction to evaluate whether trial design is a potential modifier of effect size or its direction.

Results We identified 12 trials in which tiotropium had been administered double-blind and three trials with open-label application. The overall effect for mean difference versus placebo in SGRQ total score was -2.98 units $(95 \%$ confidence interval [CI): $-3.49,-2.47)$. For the double-blind trial subgroup, mean difference versus placebo was -3.20 (95\% CI: $-3.75,-2.65)$ compared to -1.67 (95\% CI: $-3.02,-0.32)$ for open-label trials. The pvalue for interaction between subgroup and effect on SGRQ total score was 0.04 .

Conclusions In patients with COPD, trial design (double-blind versus open-label) was a statistically significant modifier of the effect of inhaled tiotropium on health-related quality of life. The modification was quantitative, resulting in a substantial underestimation of the effect of tiotropium on SGRQ total score when the administration had been open-label compared to the 'gold standard' double-blind. A subjective end point such as quality of life is particularly susceptible to bias due to patients' expectations towards the efficacy of an intervention. Therefore, the validity of studies using non-blinded designs to investigate such end points must be questioned.

\section{P250 EFFECTS OF 12 WEEKS OF ONCE-DAILY TIOTROPIUM AND OLODATEROL FIXED-DOSE COMBINATION ON EXERCISE ENDURANCE IN PATIENTS WITH COPD}

${ }^{1} \mathrm{~F}$ Maltais, ${ }^{2} \mathrm{~B}$ G Gáldiz Iturri, ${ }^{3} \mathrm{~A}$ Kirsten, ${ }^{4} \mathrm{D}$ Singh, ${ }^{5} \mathrm{~A}$ Hamilton, ${ }^{6} \mathrm{~K}$ Tetzlaff, ${ }^{7} Y$ Zhao, ${ }^{8} \mathrm{R}$ Casaburi. ' Research Center, Institut Universitaire de Cardiologie Et de Pneumologie de Québec, Université Laval, Québec, Canada; ${ }^{2}$ BioCruces Health Research Institute, Barakaldo, Spain; ${ }^{3}$ Pulmonary Research Institute at Lung Clinic Grosshansdorf, Airway Research Center North, Member of the German Center for Lung Research, Grosshansdorf, Germany; ${ }^{4}$ Medicines Evaluation Unit, University of Manchester, 